\title{
Simulation of adaptive power management circuit for hybrid energy harvester and real-time sensing application
}

\author{
M. S. Tamrin, M. R. Ahmad
}

Department of Electrical and Electronic Engineering, Universiti Teknologi PETRONAS, Malaysia

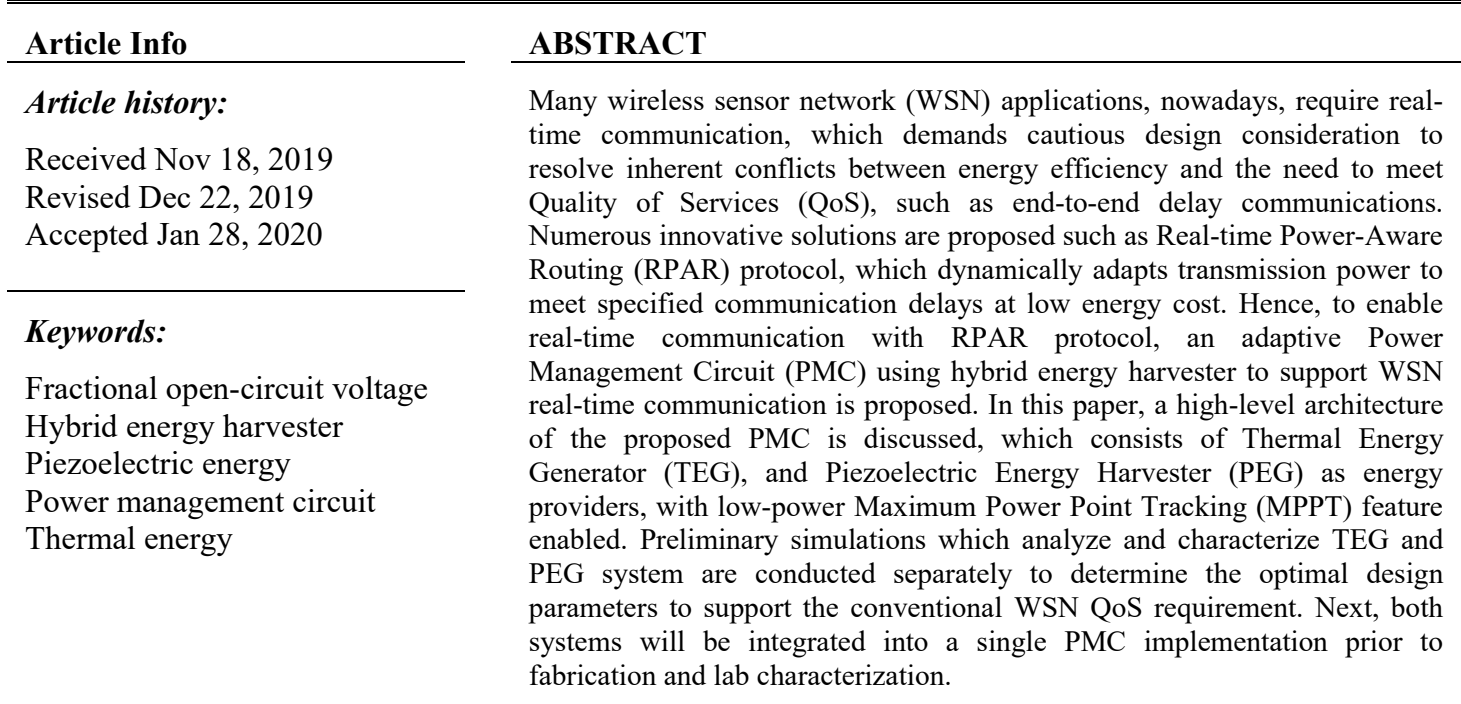

This is an open access article under the CC BY-SA license.

\section{Corresponding Author:}

M. S. Tamrin

Department of Electrical and Electronic Engineering,

Universiti Teknologi PETRONAS,

Seri Iskandar, 32610 Perak, Malaysia.

Email: shahritamrin@gmail.com

\section{INTRODUCTION}

With the recent advancement in wireless sensor applications, such as Internet of Things (IoT), ambience intelligence, and wireless sensor networks (WSN), it is expected to have 50 billion of sensor nodes by the year $2025[1,2]$. These large number of sensor nodes are normally required to operate for a long period of time, ranging from months to years. In addition to that, many WSN applications require real-time communication. For example, a surveillance monitoring system needs to alert authorities instantaneously (or within few seconds) of suspicious intruders. However, supporting real-time communications in WSNs is very challenging due to inherent conflict between stringent requirement of end-to-end delay and energy efficiency $[3,4]$. All these challenges require a very careful design consideration to manage energy resources.

Batteries are commonly used to power up WSN sensors. Although they are designed to be lowpower, eventually their batteries will be drained out, and are required to be replaced, hence incurring high maintenance cost. Therefore, energy harvesting devices have now become a preferred solution to provide cheap, clean, and unlimited alternative energy. Conventionally, energy harvesting system is mainly built upon three major components. First component is energy generator, which is used to harvest energy from 
ambiance, and convert it into electrical energy (e.g. piezoelectric, photovoltaic, and thermoelectric). Second component is called energy capture \& storage, which consists of power management circuit and storage. The last component is energy consumption, which varies based on usage condition.

However, due to relatively low output power generated by standalone energy harvester, the focus of research area has now shifted from standalone to Hybrid Energy Harvester (HEH). HEH is basically a technique to integrate multiple energy sources into a single system, which is capable to generate higher output power as compared to standalone harvester. The input energy can come from different sources, such as vibration, thermal, light, acoustic, solar, wind, radio frequency etc. Cao et al. [5] has listed down clearly conventional energy sources, and its corresponding power density and harvesting method. However, one of the key challenges for any HEH system is to design a Power Management Circuit, which can provide efficient and seamless output power to any load applications.

Over the years, many techniques have been developed to design an efficient PMC for standalone energy harvesters. In this section, we will discuss on PMC techniques used for thermal and vibration-based energy harvesters, followed by brief introduction of Maximum Power Point Tracking (MPPT) techniques, and last but not least, discussion on common architectures used in HEH systems. The main objectives of this paper are; to propose a new adaptive PMC architecture for HEH system to support real-time WSN, with overall efficiency of $>80 \%$, and to characterize TEG, and PEG sub-system separately through simulation.

Thermal-based PMC, A common example of thermal-based PMC design approach is through the integration of inductor-based boost converter and switched-capacitor buck converter into an integrated chip [6]. This Energy Harvesting IC (EHIC) is fabricated with $65 \mathrm{~nm}$ CMOS, with area less than $0.5 \mathrm{~mm}^{2}$. The proposed PMC is basically divided into two stages: Power Conversion, for which inductor-based converter is used to boost low input voltage to a suitable output voltage, with Zero Current Switching (ZCS) capability to improve efficiency during low current mode, and Power Management Unit, in which switched capacitor converter is used to regulate output voltage into multiple levels. In addition to that, in low energy condition, PMC is able to bypass switched capacitor, and the load is getting direct supply from inductor-based converter. The peak efficiency, however, varies with output voltage.

An improved version of thermal-based PMC is proposed in [7]. The Boost LC filter is equipped with a feedback loops to regulate the output voltage. Any difference between output and desired voltage is amplified and then modulated to Pulse Density Modulation (PDM) signal, which is used to control on/off of MOS power switch. The charge pump circuitry is added to reduce losses across MOS switch, by increasing the voltage of PDM signal. This PMC technique comes with feedback control loop. To achieve theoretically infinite lifetime, a system is expected to run in Energy Neutral Operation (ENO). Hence, a low-complexity Power Manager (PM) is proposed, [8] which is used to adapt with its computational load to ensure the consumed energy is equal to the harvested energy. Only if this condition meets, the system is considered to achieve ENO. The proposed PM is basically deciding and changing duty cycle of the load, according to the estimation of harvested and consumed energy, provided by a low-power super-capacitor-based energy monitor.

Typically, a desired voltage of super-capacitor when the load has converged to ENO is pre-defined. This method is very suitable for long-term monitoring applications, but not for real-time sensing application, which requires stringent end-to-end delay requirement. While majority of thermal-based PMC techniques employ DC-to-DC boost converters, a simple and novel implementation of thermal PMC is proposed in [9], which requires no complex start-up circuitry (e.g. charge pump) or typical DC-to-DC boost inductor, because TEG used in this system is capable to generate high enough voltage to drive load application directly. This PMC basically consists of two main Positive-channel MOS (PMOS) switches, MPPT control block, and one Storage Capacitor. The "brain" of this PMC design lies within MPPT control block, which is capable to control active/sleep state of the load, hence minimizing any power mismatch between TEG devices and load application. Therefore, this PMC can successfully achieve very high peak power efficiency, which is $\sim 95 \%$.

Vibration-based PMC Kong et al. [10] presented a simple and self-powered PMC, which does not require additional power to operate. The PMC is basically divided into four major components: 1) AC-to-DC converter, using full-bridge rectifier. 2) Buck-Boost Convertor which is running at Discontinuous Current Mode (DCM) is implemented to support wide range of input voltage as well as to match source impedance. 3) ultra-lower micro-controller, which is configured for MPPT and output voltage regulation. 4) Supercapacitor as storage device. The MPPT technique used for this PMC is called impedance matching.

Besides, Elie et al. [11] developed a single-switch inductorless PMC for electrostatic vibration harvester, which consists of a single switch, one biasing capacitor ( $\mathrm{C}_{\text {bias}}$ ), and three diodes. Charging or discharging state of the $\mathrm{C}_{\text {bias }}$ is controlled by this single switch. This PMC design operates in two modes: 1) Charging of Cbias, where single switch is in "open" state 2) Charging of Battery, for which single switch is in "closed" state. One great advantage of this PMC design is that it can be embedded in miniaturized system since it does not require inductor component. 
Maximum Power Point Tracking, when discussing efficiency for energy harvesting devices, one should always consider the followings: 1) conversion efficiency; 2) transfer efficiency; 3) buffering efficiency; and 4) consumption efficiency. In generic term, transfer efficiency considers amount of loss due to power transfer activity from energy source to load. Hence, there is a technique, called Maximum Power Point Tracking (MPPT), which is typically used to minimize power mismatch between energy source and load [13]. Currently, there are several MPPT techniques developed. One of them is leveraging digital signal processing [12]. Another MPPT technique is based on impedance matching $[14,15]$. This approach is not only simple to implement, but also consume very low power. The basic idea is to match between input impedance, which varies from one energy generator device to another, and inductor value of boost converter. However, due to huge tolerance of inductor itself, this technique is not be very accurate. Another MPPT technique used is called fractional open-circuit voltage (FOC) [16-18]. The open-circuit voltage (Voc) of a specific energy generator is sampled periodically to determine its maximum power point voltage (VMPP), leaving this energy generator electrically open. In this paper, we will focus on FOC technique as it is proven to achieve $\sim 99.5 \%$ of efficiency.

Common PMC Architectures for HEH System, There are few prior works done to design PMC for HEH system. The simplest method is called "complementary," as defined by [19], which mainly collects energy from a primary source, while secondary transducers is merely used to power up auxiliary circuitry, such as biasing and boot-up circuitry. As shown in Fig. 5, the Piezoelectric Generator is used during cold start-up, in which at that time, the power generated by the Thermal Generator is not sufficient to sustain the whole operation. However, this simple method does not implement maximum power point tracking (MPPT), which is crucial to ensure maximum harvesting efficiency. Besides, another common technique to harvest multiple source of energy is called "Power ORing" architecture [20-22], which offers modular approach, connecting multiple sources in parallel through diodes. Each of energy sources is independent from each other, hence could perform its own MPPT technique. The diodes is used to ensure self-synchronized operation. However, there are several disadvantages linked to this method. First, there is additional power loss due to forward voltage drop on the diodes, as well as having independent MPPT could increase cost and size of the system. The "Power ORing," architecture.

Last but not least, another more sophisticated technique commonly used in managing multisource energy harvesting is called voltage level detection method. For example, in [23] the charging of a micro battery is taken either from the voltage generated by a thermal or RF harvesting subsystem, depending on which exhibits higher voltage value. However, this cannot be applied for loads that require constant voltage supply [24]. In [25], an improved technique is used: each input is connected to the output at pre-defined period of time, provided its respective voltage surpasses the determined voltage threshold.

\section{RESEARCH METHODOLOGY}

\subsection{Specification definition}

Since each and every WSN applications has its own requirement, determining specific Quality of Services (QoS) is a crucial step. Table 1 shows a QoS for specific Structural Montoring Application.

Table 1. QoS for structural monitoring application [8]

\begin{tabular}{cccccc}
\hline & $\begin{array}{c}\text { Efficiency } \\
(\%)\end{array}$ & $\begin{array}{c}\text { Nominal Voltage } \\
(\mathrm{v})\end{array}$ & Sleep & $\begin{array}{c}\text { Average Current Requirements (A) } \\
\text { Active } \\
\text { (Normal) }\end{array}$ & Active (Performance) \\
\hline $\begin{array}{c}\text { Quality of Service } \\
(\mathrm{QoS})\end{array}$ & $>80$ & 3.5 & $175 \mathrm{e}-6$ & $3.5 \mathrm{e}-3$ & $\begin{array}{c}\text { Min. 20\% higher than normal } \\
\text { operation }\end{array}$ \\
\hline
\end{tabular}

\subsection{Architecture Definition}

In this paper, we propose an adaptive PMC, which is capable to integrate inputs from two energy harvesters, which are TEG \& PEG. This proposed PMC integrates some of the elementary techniques from the previous works into one single architecture. For example, the proposed PMC applies basic "complementary" technique to meet specified workload requirement. For structural monitoring application, which stays in sleep mode for most of the time, TEG is used to provide energy during sleep mode, while PEG is during active mode. Besides, the proposed PMC also implements MPPT technique for TEG sub-system. Unlike "Power ORing," the TEG and PEG is not independent from each other - they are controlled by Pulse Generator, which already have pre-determined timing information between sleep and active mode. This Pulse Generator is used to control the "ON" and "OFF" state for each sub-system.

Int J Pow Elec \& Dri Syst, Vol. 11, No. 2, June 2020 : 658 - 666 
The high-level architecture of proposed PMC design is shown in Figure 1. The proposed PMC architecture consists of several main blocks, and components. For example, Pulse Generator is used to control switching between TEG and PEG supply. The pulse is generated based on the loading conditions, i.e. sleep mode $=$ TEG is activated; active mode $=$ PEG is activated. Enable Generator block, which consists of 2-stage comparator and latch circuitry is critical to ensure TEG system operates within tolerated supply, hence maximizing power transfer from TEG harvester to the load. PWM Generator, and the Error Amplifier are used as a control loop to ensure PEG system is regulated into desired voltage. Full-wave rectifier, together with ripple-cancellation capacitor, $\mathrm{C} 1$, are the major component of the AC-to-DC voltage converter. Comparator and Phase Delay blocks are added to ensure seamless transition between TEG and PEG subsystem

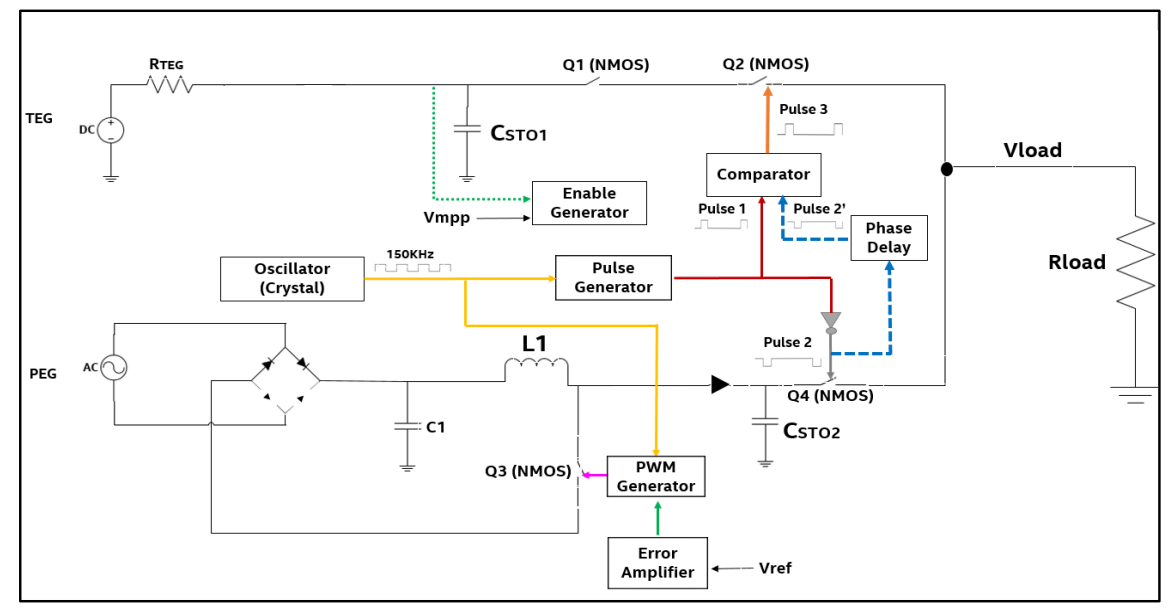

Figure 1. High-level diagram of the Proposed PMC Architecture

Details implementation for each power states (i.e. sleep/active) is described by flowcharts in Figure 2 and Figure 3.

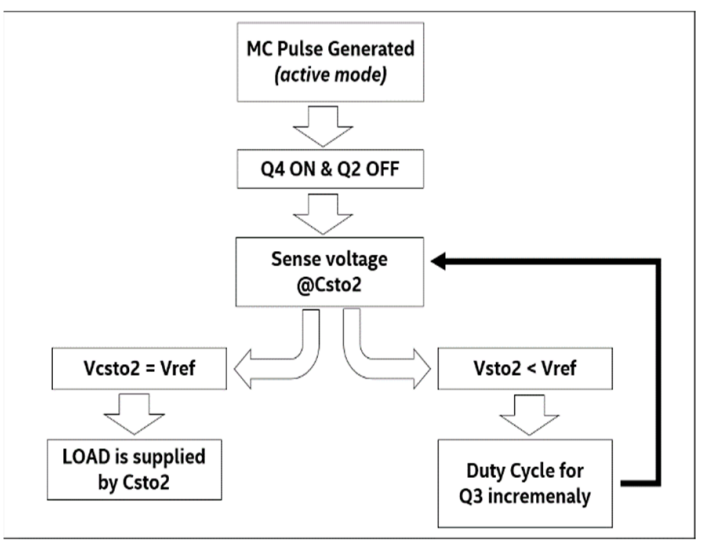

Figure 2. Proposed architectural flow during active mode

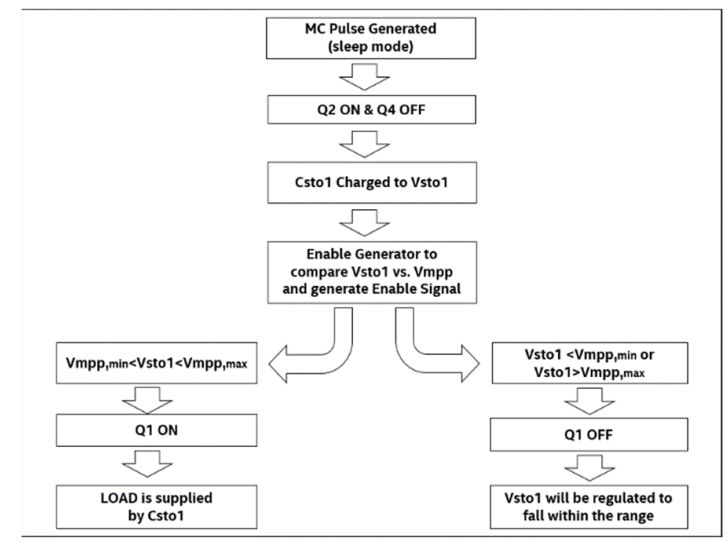

Figure 3. Proposed architectural flow during sleep mode

The main challenges to design PMC for HEH system is to integrate sub-systems seamlessly. Therefore, to ensure smooth transition, the PMC required definite overlapped time between two-subsystems, as shown in the Figure 4. 


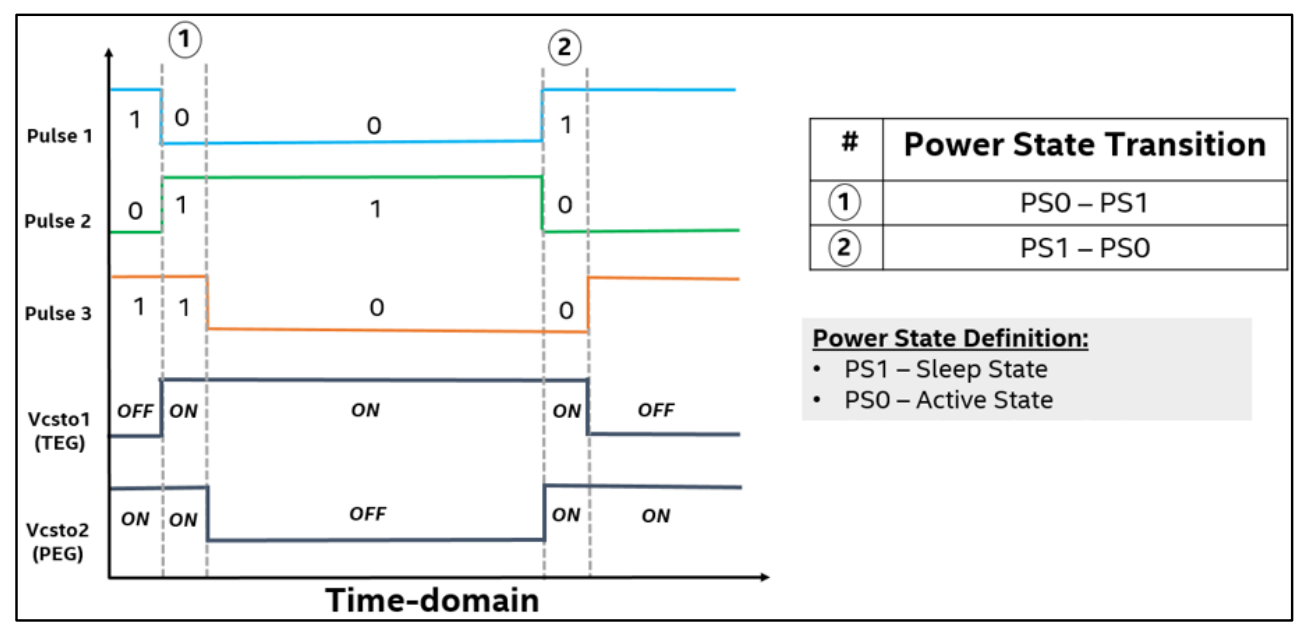

Figure 4. Power-state transition policy

\section{RESULTS AND ANALYSIS}

A feasibility study of the proposed PMC architecture is carried out using HSPICE software 1) To characterize design parameters for PEG system in order to meet QoS during active mode; 2) To analyze feasibility of TEG to meet efficiency target.

\subsection{Characterization of PEG}

PEG is basically a generator that converts vibration generated from steps into electrical energy. In this [26]. PEG system typically consists of two parts: AC-to-DC converter, and DC-to-DC boost converter. For AC-to-DC converter, we are evaluating for optimal capacitor to minimize voltage ripple. Meanwhile, for boost converter, we are tuning duty cycle, switching frequency, and inductor to find the optimal solutions. For this simulation, we assumed 5-layer piezoelectric thick films as our PEG device, which has 5.3x higher output current vs. single layer PEG device, 34x smaller matching impedance [27].

First, we characterized the rectifying circuit. Figure 5 shows the converted DC voltage, together with its corresponding voltage ripple for varying capacitance value. Based on this results, minimum capacitance of $10 \mathrm{uF}$ is required to meet sub-mV voltage ripple. We, then characterized DC-DC boost converter by sweeping crucial design parameters. Figure 6 to Figure 7 show sensitivitities of different design parameters such duty cycle, switching frequency, and inductor values.

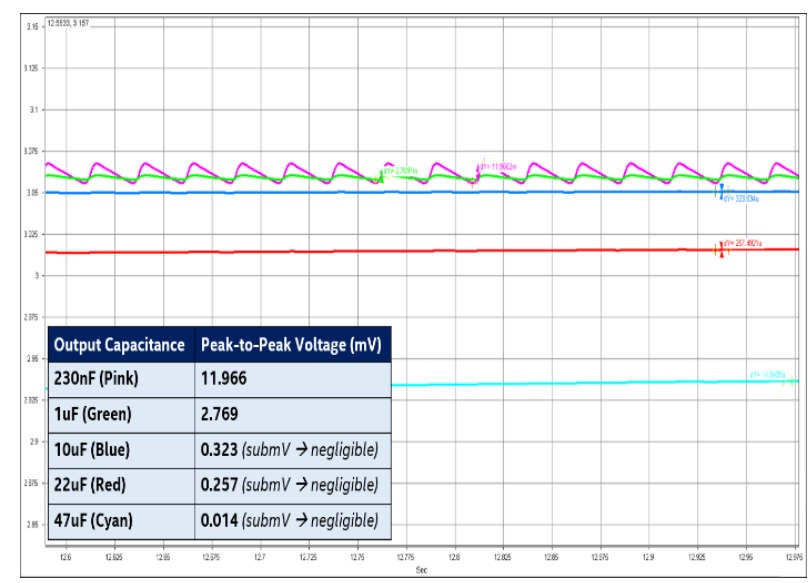

Figure 5. Voltage ripple due to AC-to-DC conversion 


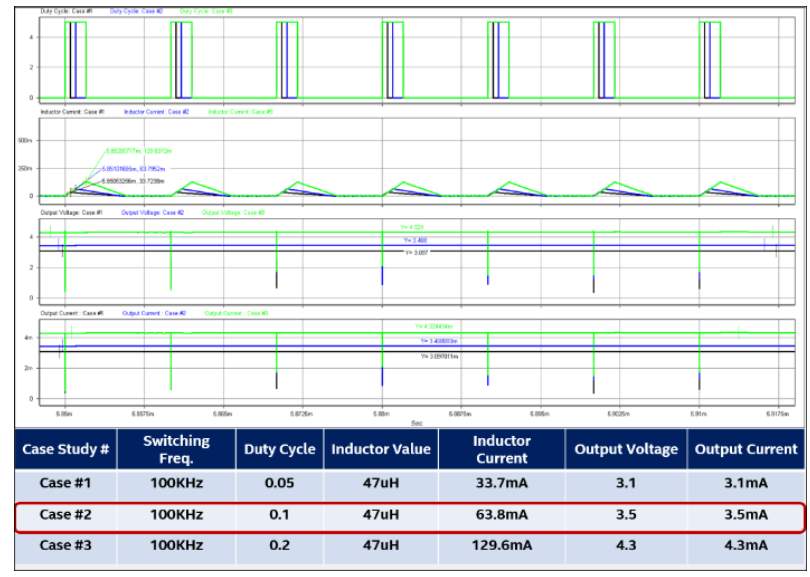

Figure 6. Duty cycle sensitivity study for DC/DC boost converter

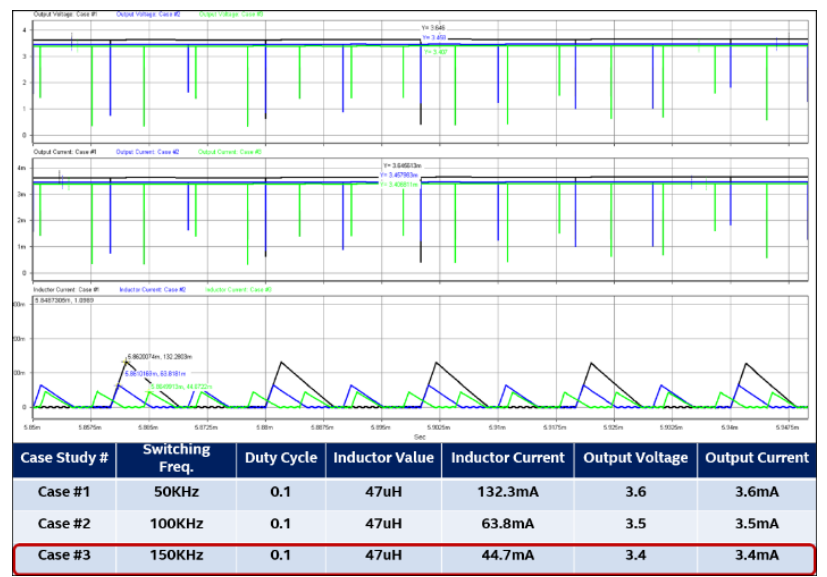

Figure 7. Switching freq sensitivity study for DC/DC boost converter

Based on the preliminary simulation results, a recommendation for optimal design of the PEG system to meet specified QoS is shown in Table 2.

Table 2. Recommended design parameters for peg system

\begin{tabular}{|c|c|c|c|}
\hline Design Paramaters & $\begin{array}{c}\text { Proposed Value } \\
\text { (for normal active operation) }\end{array}$ & Qos & Simulated Results \\
\hline Duty Clycle & 0.10 & Output Voltage & $3.55 \mathrm{~V}$ \\
\hline Switching Frequency & $150 \mathrm{KHz}$ & Output Current & $3.55 \mathrm{~mA}$ \\
\hline Inductor & $22 \mathrm{uF}$ & Output Power & $12.3 \mathrm{~mA}$ \\
\hline Output Capacitor & $47 \mathrm{uF}$ & Inductor Current & $96 \mathrm{~mA}$ \\
\hline
\end{tabular}

\subsection{Characterization of TEG}

Unlike the PEG System, TEG efficiency is very crucial to ensure we can meet $>80 \%$ efficiency requirement. Based on Yoon, et al. [7], due to the linear I-V characteristics of TEG, Maximum Power Point (MPP), for each TEG device can easily be determined by (1) and (2).

$\mathrm{Vmpp}=1 / 2 \mathrm{Voc}$

$\operatorname{Pmax}=\operatorname{Voc}^{\wedge} 2 / 4 \mathrm{RT}$

Hence, by knowing the RT \& Voc of any TEG device, we can determine its corresponding Vmpp. Figure 8 shows MPP Voltage (Vmpp) for TEG device with Voc $=6 \mathrm{~V}$ and RT $=300 \mathrm{KOhm}$. 


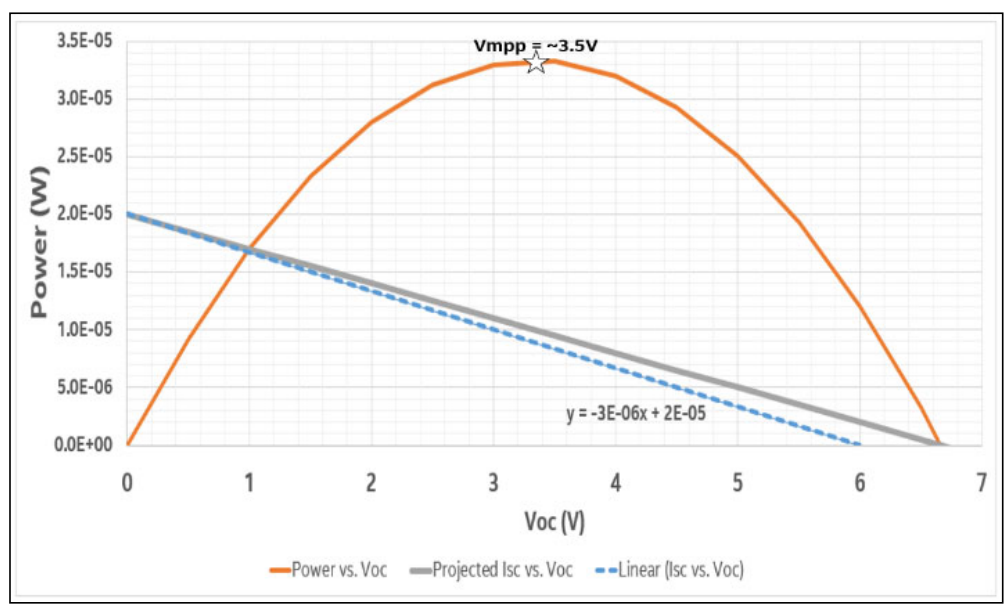

Figure 8. Maximum power point versus Voc.

Figure 9 shows that maximum power can be harvested from this speficic TEG is $\sim 3.5 \mathrm{~V}$, meaning that if we can regulate our TEG system to $\sim 3.5 \mathrm{~V}$, our power efficiency will be almost $100 \%$. However, achieveing $100 \%$ efficiency is nevertheless unrealistic. Hence, for this study, we are only targeting efficiency of $>80 \%$, which is typical for buck-boost platform regulator. Therefore, we can allow Vsto1 to be varied slightly from its optimal Vmpp.

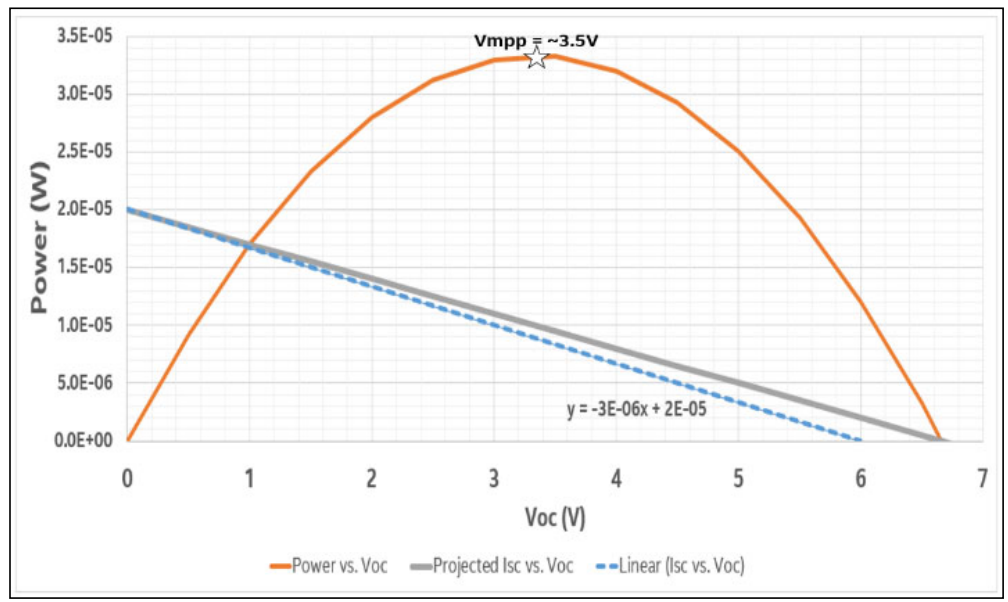

Figure 9. Projected power efficiency versus Voc.

Other than that, for this architecture to work decently, we need to guarantee PEG can sustain sleep current for long period of time. This is actually related to capacitor selection of Csto1. The bigger the capacitor, the longer it can sustain. However, this could impact the charging time of capacitor as well. Figure 10 shows linear correlation between sustain time vs. capacitance value, assuming Vsto1 varies between 4.25 $\mathrm{V}$ and $2 \mathrm{~V}$ (i.e. $>80 \%$ efficiency) for $175 \mathrm{uA}$ loading current. 


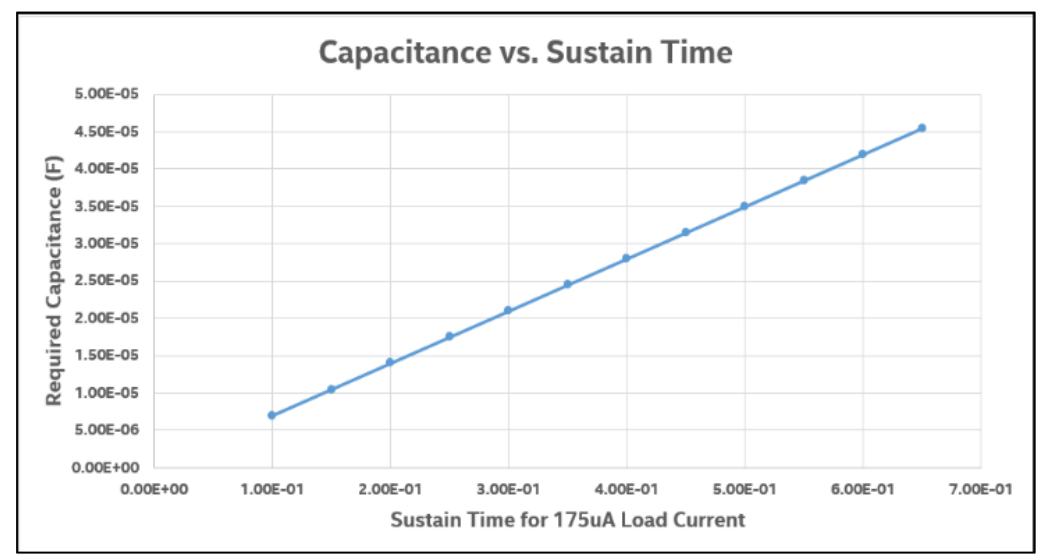

Figure 10. Capacitance vs. sustain time for 175 ua load current.

\section{CONCLUSION}

In summary, based on preliminary simulation results, we can see line of sight to meet conventional WSN QoS requirement for structural monitoring application. Optimal design parameters for PEG has also been identified to support output current of $3.5 \mathrm{~mA}$ during active state. Besides, TEG is projected to sustain output current of $175 \mathrm{uA}$, which is required during sleep state, for $>600 \mathrm{~ms}$, with efficiency of $>80 \%$ using $47 \mathrm{uF}$ capacitor. In addition to that, relationship of output voltage of TEG to power efficiency has also been characterized in this paper. Next step is to integrate both systems and to implement our power-state transition policy, which is key component of our proposed PMC architecture.

\section{ACKNOWLEDGEMENTS}

Authors would like to acknowledge the supports given by the Electrical and Electronic Department of Universiti Teknologi PETRONAS in providing the facilities to perform the simulations and not to forget the Yayasan UTP for providing the funding.

\section{REFERENCES}

[1] J. J. Estrade-Lopez, A. Abuellil, Z. Zeng, E.S. Sinencio, "Multiple Input Energy Harvesting for Autonomous IoT End-Nodes," Journal of Low Power Electronics and Applications, Mar 2018.

[2] L. Atzori, A. Iera, and G. Morabito, "The Internet of Things: A survey" in Computer Networks," vol. 54, no 15, pp. 2787-2805, Oct 2010.

[3] O. Chipara O, H. Zhimin, X. Guoliang, C. Qin, W. Xiaorui, L. Chenyang, S. John, A. Tarek, "Real-time Power Aware Routing in Sensor Networks," IEEE, 2006.

[4] C. Mario, G.C. Daniel, F. Francisco F, and K. Xianjie, "New challenges of real-time wireless sensor networks: Theory and applications," International Journal of Distributed Sensor Networks, September 2016.

[5] S. Cao, and L. Jianqing, "A survey on ambient energy sources and harvesting methods for structural health monitoring applications," Advances in Mechanical Engineering, vol. 9, no. 4, pp. 1-14, 2017.

[6] M. Alhawari, D. Kilani, M. Baker, S. Hani, and M. Ismail, "An Efficient Thermal Energy Harvesting for Power Management for uWatt Wearable Biochips," IEEE, 2016.

[7] H. Lhermet, C. Condemine, M. Plissonnier, and R. Salot, "Efficient Power Management Circuit: Thermal Energy Harvesting to Above-IC Microbattery Energy Storage," IEEE International Solid-State Circuits Conference, 2007.

[8] L.E. Trong Nhan, P. Alain, S. Olivier, B. Olivier, and B. Cecile, "Duty-Cycle Power Manager for Thermal-Power Wireless Sensor Networks," 2013 IEEE $24^{\text {th }}$ International Symposium on Personal, Indoor and Mobile Radio Communications: MAC and Cross-Layer Design Track, 2013.

[9] E. J. Yoon, J. T. Park, and C. G. Yu, "Thermal energy harvesting circuit with maximum power point tracking control for self-powered sensor node applications," Frontiers of Information Technology \& Electronic Engineering, February 2018.

[10] N. Kong, T. Chchran, D. Sm-Ha, H. C. Lin, and D. J. Inman, "A Self-powered Power Management Circuit, for Energy Harvested by a Piezoelectric Cantilever," IEEE, pp. 215-2160, 2010.

[11] E. Lefeuvre, J. Wei, H. Mathias, and F. Costa, "Single-Switch Inductorless Power Management Circuit for Electrostatic Vibration Energy Harvesters" IEEE $13^{\text {th }}$ International New Circuits and System Conferences (NEWCAS), Jun 2015.

[12] R.Y. Kim, and J.S. Lai, "A seamless mode transfer maximum power point tracking controller for thermoelectric generator applications," IEEE Trans Power Electron, 2008. 
[13] A.A. Abdulrazzaq, and A.H. Ali, "Efficiency Performances of Two MPPT Algorithms for PV Systems with Different Solar Panels Irradiances," International Journal of Power Electronics and Drive System (IJPEDS), vol. 9, no. 4, pp. 1755-1764, 2018.

[14] Y. K. Ramadass and A. P. Chandrakasan, "A battery-less thermoelectric energy harvesting interface circuit with $35 \mathrm{mV}$ startup voltage," IEEE J Sol-State Circ, 2011.

[15] W. Danang, and L.H. Pratomo, "Impedance Matching Method in Two-Stage Converters for Single Phase PV-Grid System," International Journal of Electrical and Computer Engineering (IJECE), 2015.

[16] J. Kim, and C. Kim, "A DC-DC boost converter with variation tolerant MPPT technique and efficient ZCS circuit for thermoelectric energy harvesting applications," IEEE Trans Power Electron, 2013.

[17] B. Athira, V. Greeshma. J. Johnson, "Analysis of Different MPPT Techniques," International Journal of Advanced Research in Electrical, Electronics, and Instrumentation Engineering, vol. 5, 2016.

[18] J. Ahmad, "Fractional open circuit voltage based maximum power point tracker for photovoltaic arrays," In Proceedings of the 2nd International Conference on Software Technology and Engineering, San Juan, PR, USA, vol. 1, pp. V1-247-V1-250, Oct 2010.

[19] C. Vanhecke, L. Assouère, A. Wang, P. Durand-Estèbe, F. Caignet, et al., "Multisource and Battery-free Energy Harvesting Architecture for Aeronautics Applications," IEEE Transactions on Power Electronics, Institute of Electrical and Electronics Engineers, vol. 30, no. 6, pp. 3215-3227, 2015.

[20] D. Carli, D. Brunelli, L. Benini, M. Ruggeri, "An effective multi-source energy harvester for low power applications," Design, Automation \& Test, Mar 2011.

[21] H. Li, G. Zhang, R. Ma, and Z. You, "Design and Experimental Evaluation on an Advanced Multisource Energy Harvesting System for Wireless Sensor Nodes," Sci. World J, 2014.

[22] Y.K. Tan, and S.K. Panda, "Energy Harvesting from Hybrid Indoor Ambient Light and Thermal Energy Sources for Enhanced Performance of Wireless Sensor Nodes," IEEE Trans. Ind. Electron. 58, 4424-4435, 2011.

[23] H. Lhermet, C. Condemine, M. Plissonnier, R. Salot, P. Audebert, and M. Rosset, "Efficient Power Management Circuit: Thermal Energy Harvesting to Above-IC Micro battery Energy Storage," IEEE International Digest of Technical Papers Solid-State Circuits Conference, pp. 62-587, 2008.

[24] S.A. Abd. Hamid, E.H Majlan, R.E. Rosli, W.R. Wan Daud, R. Mohamed, T. Husaini, and R. Sitanggang, "Energy Management Strategy for A Fuel Cell/Ultra capacitor/Battery Hybrid System for Portable Applications," Malaysia Journal of Analytical Sciences, April 2016.

[25] T. Kang, S. Kim, C. Hyoung, S. Kang, K. Park, "An Energy Combiner for a Multi-Input Energy-Harvesting System," IEEE Trans. Circuits Syst. II Express Briefs 62, pp. 911-915, 2015.

[26] S.S. Iswanto, F. Mujahid, K.T. Putra, N.P. Apriyanto, and Y. Apriani, "Energy Harvesting on Footsteps Using Piezoelectric based on Circuit LCT3588 and Boost up Converter," International Journal of Electrical and Computer Engineering (IJECE), vol. 8, no. 6, pp. 4104-4110, Dec 2018.

[27] M. S. Woo, J. H. Ahn, J. H. Eom, W. S. Hwang, J. H. Kim, C. H. Yang, G. J. Song, S. D. Hong, J. P. Jhun, T. H. Sung, "Study on increasing output current of piezoelectric energy harvester by fabrication of multilayer thick film," Sensors and Actuators A: Physical, pp 524-534, 2018.

\section{BIOGRAPHIES OF AUTHORS}
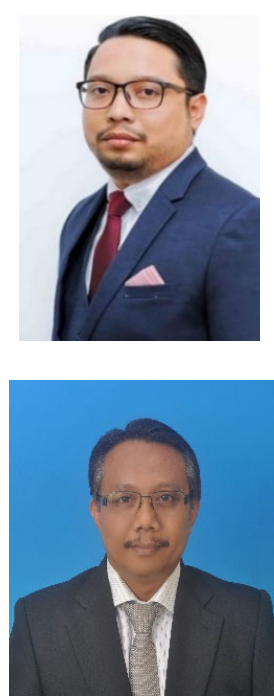

Mohamad Shahrir bin Tamrin obtained his Bachelor of Electrical Engineering (Hons) in 2011 from Stevens Institute of Technology USA. He is currently holding a position of Analog Engineer in Intel Malaysia for the past 8 years. On top of that, he is also currently pursuing a MSc in Electrical Engineering from Universiti Teknologi PETRONAS Malaysia. His research interest is mainly on Power Management Circuit for Hybrid Energy Harvesting System.

Dr. Mohamad Radzi Ahmad received his BSc. in Electrical Engineering from Purdue University School of Engineering and Technology Indianapolis USA in 1991, MSc. in Electronics System Design Engineering from Universiti Sains Malaysia in 2010, and $\mathrm{PhD}$ in Electrical and Electronics Engineering from Universiti Teknologi PETRONAS Malaysia in 2014. He joined Universiti Teknologi PETRONAS in 2016, where he is currently a Senior Lecturer in the Electrical and Electronic Engineering Department. Prior to joining UTP, Dr Radzi had 20 years of professional experience with electronic industries such as Intel, Avago, Western Digital and Fairchild Semiconductor, and held various positions ranging from Senior Manager to Product R\&D Engineer. 